\title{
Family recovery after death of a child
}

\author{
J H BAUMER, ${ }^{*}$ J WADSWORTH, $\dagger$ AND B TAYLOR $\ddagger$ \\ ${ }^{*}$ Department of Child Health, Freedom Fields Hospital, Plymouth, and Departments of $\dagger$ Community \\ Medicine and $¥$ Paediatrics, St Mary’s Hospital Medical School, London
}

SUMMARY Children from a national birth cohort living in families in which a sibling had died or been stillborn were compared with children living in similarly structured families where no such tragedy had occurred by a number of health, developmental, and behavioural outcomes. Surprisingly little ill effect from a sibling death (occurring either before or after the birth of study children) was apparent at the age of 5 years. Families experiencing a stillbirth or death of a child were socially disadvantaged. Even allowing for this and other likely intervening factors, however, a child whose adjacent sibling had died was significantly more liable to bronchitis or wheezing during the first 5 years. Mothers who had experienced the death of a child since the study child's birth had high scores on a psychological screening test, and were more likely to be single parents. Mothers who had lost a child were more likely to smoke during the next pregnancy. No significant differences between cases and control subjects were detected on other health, behavioural, or developmental outcomes.

Stillbirth or death of a child appears to have little measurable effect on siblings assessed at 5 years of age. This study does not exclude important longer term psychological effects from sibling death.

Intense parental grieving may follow a stillbirth or the death of a child ${ }^{12}$; a mother's reaction in such circumstances seems to be as strong as that of a newly bereaved widow. ${ }^{3}$ Surviving children may be severely affected by the death of a sibling, ${ }^{4-8}$ and children conceived subsequently have been reported to be liable to a range of adverse behaviour, including overprotection or rejection. ${ }^{7} 910$

Death in childhood is rare in developed societies; even perinatal deaths are uncommon, and becoming fewer. Perinatal and childhood mortality, however, is higher in socially disadvantaged families ${ }^{11}{ }^{12}$; observations in bereaved families, including children's reactions, may be biased by this fact. None of the studies reporting the effects of the death of a sibling on a child have attempted to control for social factors, and most reflect the experience of specialised units that may give unrepresentative views of families' reactions. A total population survey should provide more generally applicable conclusions.

In the present study of a national cohort of British children born in 1970 we have assessed the effect of sibling death on surviving children, and those conceived subsequently, at the age of 5 years, making allowances for likely confounding social and environmental factors.

\section{Subjects and methods}

The Child Health and Educational Study (CHES) ${ }^{1314}$ is a continuing longitudinal survey of children studied in the neonatal period in the British Births Survey. ${ }^{12}{ }^{15}$ The cohort originally included all the children born in the United Kingdom during 5-11 April 1970. In 1975 children born in that week and living in England, Scotland, and Wales were traced; 12743 subjects were studied out of a possible 16015 from the birth survey (79.6\%). When the parents were interviewed at home five years after the original survey health visitors gave them specially designed development and behavioural tests and gathered over 500 items of social, family, and health data. The study population for the present analyses comprised those 12246 children who were singleton births living with their natural mothers at the time of the five year survey.

From the history, families were identified in which at least one sibling of the study child had been stillborn or had died in childhood. Sibling deaths occurring before the birth of the study child were identified at the interview at birth, and subsequent deaths at the five year interview. The information was recorded as either stillbirths and deaths in the 
Table 1 Details of the family structures of the study and control groups

\begin{tabular}{|c|c|c|c|c|c|c|}
\hline & \multicolumn{2}{|l|}{ Group I } & \multicolumn{2}{|l|}{ Group 2} & \multicolumn{2}{|l|}{ Group 3} \\
\hline & $\begin{array}{l}\text { Sibling death } \\
\text { No }(\%)\end{array}$ & $\begin{array}{l}\text { Control } \\
\text { No }(\%)\end{array}$ & $\begin{array}{l}\text { Sibling death } \\
\text { No }(\%)\end{array}$ & $\begin{array}{l}\text { Control } \\
\text { No }(\%)\end{array}$ & $\begin{array}{l}\text { Sibling death } \\
\text { No }(\%)\end{array}$ & $\begin{array}{l}\text { Control } \\
\text { No }(\%)\end{array}$ \\
\hline \multicolumn{7}{|l|}{ No of older } \\
\hline live siblings: & & & & & & \\
\hline 0 & $13(2 \cdot 9)$ & $0(0 \cdot 0)$ & $121(46 \cdot 4)$ & $0(0 \cdot 0)$ & $76(62 \cdot 3)$ & $2989(64 \cdot 4)$ \\
\hline 1 & $143(32 \cdot 0)$ & $0(0 \cdot 0)$ & $78(29.9)$ & $4008(56 \cdot 5)$ & $22(18 \cdot 0)$ & $1031(22 \cdot 2)$ \\
\hline 2 & $117(26 \cdot 2)$ & $1804(58 \cdot 6)$ & $28(10 \cdot 7)$ & $1804(25 \cdot 5)$ & $13(10 \cdot 7)$ & $364(7 \cdot 8)$ \\
\hline 3 & $77(17 \cdot 2)$ & $739(24 \cdot 0)$ & $20(7 \cdot 7)$ & $739(10 \cdot 4)$ & $5(4 \cdot 1)$ & $144(3 \cdot 1)$ \\
\hline 4 or more & $97(21.7)$ & $537(17 \cdot 4)$ & $14(5 \cdot 4)$ & $537(7 \cdot 6)$ & $6(4.9)$ & $112(2 \cdot 4)$ \\
\hline \multirow{2}{*}{\multicolumn{7}{|c|}{$\begin{array}{l}\text { No of younger } \\
\text { live siblings: }\end{array}$}} \\
\hline & & & & & & \\
\hline 0 & $345(77 \cdot 2)$ & $2460(79.9)$ & $140(53 \cdot 6)$ & $5437(76 \cdot 7)$ & $67(54.9)$ & $0(0 \cdot 0)$ \\
\hline 1 & $86(19 \cdot 2)$ & $513(16 \cdot 7)$ & $101(38 \cdot 7)$ & $1413(19.9)$ & $48(39 \cdot 3)$ & $3952(85 \cdot 2)$ \\
\hline 2 or more & $16(3 \cdot 6)$ & $107(3 \cdot 5)$ & $20(7 \cdot 7)$ & $238(3.4)$ & $7(5 \cdot 7)$ & $688(14 \cdot 8)$ \\
\hline Total & 447 & 3080 & 261 & 7088 & 122 & 4640 \\
\hline
\end{tabular}

first 7 days or deaths after 7 days. Of the sibling deaths, $70 \%$ occurred in the perinatal period.

For comparison, three case and three control groups were formed, the control groups with no childhood deaths having the family structure that would have existed had the sibling not died. Group 1 comprised 447 families in which an older sibling had died before the birth of the study child, with at least one intervening living sibling. The 3080 control families comprised all families with at least two children older than the study child and no reported sibling death. Group 2 comprised 261 families in which the next older sibling to the study child had died previously. The 7088 control families had at least one child older than the study child. Group 3 comprised 122 families in which the next younger sibling to the study child had died. The 4640 control families had at least one sibling younger than the study child. Data from a fourth group (families with one living sibling born after the CHES child, and then a sibling death) were not analysed as the numbers were too small.

Details of the groups including the numbers of study children and the family structure are shown in table 1; the control groups are not mutually exclusive. The proportions of perinatal and postperinatal deaths were similar in all the study groups. Because there was no other information available about the age of those who died subsequently, the present results combine perinatal deaths and those occurring later in childhood; study children who experienced a stillbirth and those who experienced the death of a living sibling were considered together.

The outcomes listed below were assessed, ${ }^{13}{ }^{14}$ and each group of sibling deaths was compared with the appropriate control population. (1) Problems with excessive crying, feeding difficulties, or disturbances of sleep during the first 6 months of life. (2) At least one episode of wheezing or bronchitis during the first 5 years. (3) The number of admissions to hospital during the first 5 years. (4) The number of accidents requiring medical advice or treatment. (5) The child's height at 5 years. (6) An estimate of the child's behaviour by the mother (the Rutter A scale). (7) An estimate of her own psychological state by the mother (the 24 item malaise inventory). The more negative the score, the more depressed, miserable, nervous, or worried was the mother. (8) An assessment of the child's vocabulary (the English picture vocabulary test). (9) An assessment of the child's visuomotor coordination skill.

The variables listed below were collected at the birth or 5 year interviews and were used in the multivariate analyses (logistic multiway contingency table analysis ${ }^{16}$ for the discrete outcomes, 1-4 above, and analysis of covariance for the scaled outcomes, 5-9 above). The number of siblings, birth rank, maternal age, the study child's gestational age, maternal smoking during the pregnancy of the study child, whether or not the natural father lived with the family at the time of the 5 year interview, the number of household moves during the child's first 5 years, and the social index (a composite assessment of socioeconomic state derived from indices of domestic crowding, parental education, tenure of accommodation, type of neighbourhood, and father's occupation $)^{13}$ at the study child's fifth birthday. Where there was missing information on 
any variable (always less than $5 \%$ and for most less than $2 \%$ ) the subject was omitted from that particular analysis, thus the figures in the results exclude missing values.

\section{Results}

Table 2 shows the differential rates between case and control groups where there were significant differences in the outcomes of the children in any of the study groups. Study children who had a younger or older adjacent sibling who died were more liable to lower respiratory symptoms than those in families in which no death had occurred. Early sleeping problems occurred more often in children from families in which an older sibling (with an intervening living sibling) had died or was stillborn. Sleeping problems were no more frequent when it was the next older sibling that had died or was stillborn.

There were no significant differences between children from families in which a sibling had died and children from families with similar structure in which no child had died in assessment of behaviour, vocabulary, visuomotor coordination, height at 5 years, the likelihood of accidents or admission to hospital in early life, and crying or feeding problems during the first 6 months of life.

Though each control group reflects the likely family size and sibling relationships if a death had not occurred in the study group, there are many

Table 2 Percentage rates of problems or illnesses during the first 5 years of life in which significant differences were found between sibling death and control groups. Figures in parentheses are those obtained after adjustment for intervening variables in logistic multiway contingency table analysis

\begin{tabular}{|c|c|c|c|c|c|c|c|c|c|}
\hline \multirow[b]{3}{*}{$\begin{array}{l}\text { Slecping problems } \\
\text { in first } 6 \text { months }\end{array}$} & \multicolumn{3}{|c|}{ Group I } & \multicolumn{3}{|c|}{ Group 2} & \multicolumn{3}{|c|}{ Group 3} \\
\hline & \multicolumn{2}{|c|}{ Sibling death } & \multirow{2}{*}{$\begin{array}{l}\text { Control } \\
9 \cdot 6 \\
9 \cdot 7)\end{array}$} & \multicolumn{2}{|c|}{ Sibling death } & \multirow{2}{*}{$\begin{array}{l}\text { Control } \\
11 \cdot 2\end{array}$} & \multicolumn{2}{|c|}{ Sibling death } & \multirow{2}{*}{$\frac{\text { Control }}{15 \cdot 5}$} \\
\hline & $\begin{array}{r}12 \cdot 8 \\
(13 \cdot 1\end{array}$ & * & & $13 \cdot 9$ & & & $9 \cdot 8$ & & \\
\hline Bronchitis & $19 \cdot 6$ & & $18 \cdot 5$ & $\begin{array}{r}23 \cdot 6 \\
(22 \cdot 5\end{array}$ & NS & $\begin{array}{l}17 \cdot 4 \\
18 \cdot 3)\end{array}$ & $\begin{array}{r}26 \cdot 4 \\
(26 \cdot 1\end{array}$ & $* *$ & $\begin{array}{l}15 \cdot 9 \\
15 \cdot 6)\end{array}$ \\
\hline Wheczing & $21 \cdot 4$ & & 2()$\cdot 7$ & $\begin{array}{r}27 \cdot 1 \\
(26 \cdot 1\end{array}$ & $\begin{array}{l}* * \\
*\end{array}$ & $\begin{array}{l}19 \cdot 9 \\
19 \cdot 9)\end{array}$ & $24 \cdot 2$ & & $17 \cdot 9$ \\
\hline Total No & 447 & & 3080 & 261 & & 7088 & 122 & & 4640 \\
\hline
\end{tabular}

${ }^{*} \mathrm{p}<0 \cdot 05 ;{ }^{* *} \mathrm{p}<0 \cdot\left(01 ;{ }^{* * *} \mathrm{p}<0 .(0) 1 ;\right.$ percentages exclude those with missing results.

Table 3 Percentage differences in social factors between sibling death and control groups

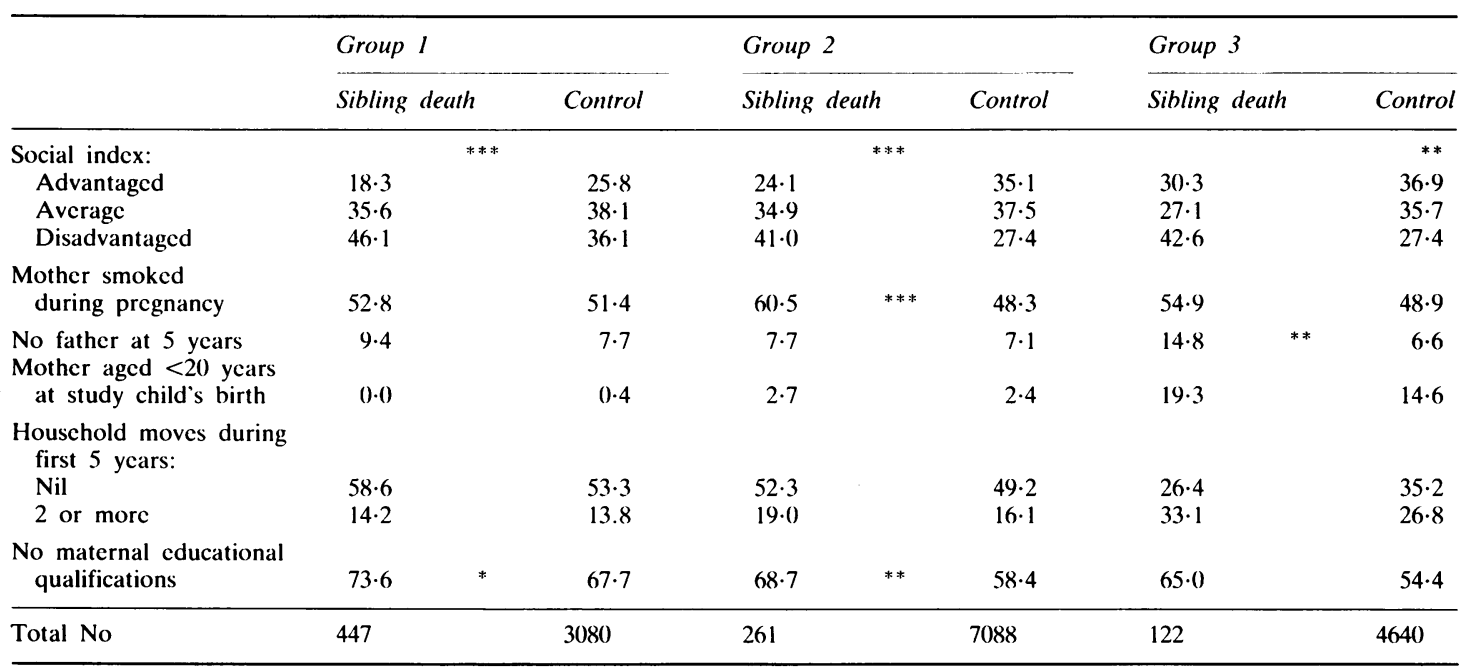

${ }^{*} \mathrm{p}<0.05 ;{ }^{* *} \mathrm{p}<0.01 ;{ }^{* * *} \mathrm{p}<0 \cdot 001$; percentages exclude those with missing results. 
Table 4 Standardised scores for maternal malaise

\begin{tabular}{|c|c|c|c|c|c|c|c|}
\hline \multirow{2}{*}{$\begin{array}{l}\text { Mean maternal } \\
\text { malaise score }\end{array}$} & \multicolumn{2}{|l|}{ Group 1} & \multicolumn{2}{|l|}{ Group 2} & \multicolumn{3}{|l|}{ Group 3} \\
\hline & Sibling death & Controls & Sibling death & Controls & Sibling death & & Controls \\
\hline $\begin{array}{l}\text { Unadjusted } \\
\text { Adjusted }\end{array}$ & $-0 \cdot 19$ & $-0 \cdot 11$ & -0.05 & -0.00 & $\begin{array}{l}-0 \cdot 34 \\
-0.26\end{array}$ & $\begin{array}{r}* * * \\
* *\end{array}$ & $\begin{array}{l}-0.03 \\
-0.03\end{array}$ \\
\hline
\end{tabular}

${ }^{* * *} \mathrm{p}<0.001 ;{ }^{* *} \mathrm{p}<0 \cdot 01$; unadjusted results are shown together with those obtained after allowing for intervening factors in an analysis of covariance for the one result with a significant difference between cases and controls on the unadjusted results.

other social, environmental, and possibly biological influences that should be considered before concluding that observed problems do result from an event such as a sibling death. Table 3 shows the distribution of the various social factors considered for each group. Families who experienced the death of a child were socioeconomically disadvantaged compared with their controls. The mothers of children with a dead older sibling were less likely to have any educational qualifications, and those whose child immediately before the study child had died were more likely to have smoked during the pregnancy of the study child. Families in which a sibling younger than the study child had died were more likely than their controls to be without a father figure when the study child was 5 years old.

The results when these possible confounding factors were taken into consideration in multivariate analyses are shown in parentheses in table 2. The marginally significant associations with early sleeping problems were unaffected, but the signficance of the associations with bronchitis and wheezing were attenuated. The most important associations with lower respiratory symptoms were maternal smoking during pregnancy and the social index $(\mathrm{p}<0.001$ for both, even allowing for possible intervening factors).

The effect of a child's death on the mother's psychological state assessed by the malaise scale is shown in table 4 , with unadjusted results for the sibling death groups and their controls together with the results when intervening factors were considered in an analysis of covariance. Mothers who had recently lost a young child were likely to have high scores, significantly different from controls (with only slight attenuation after allowing for intervening variables). There was no signficant association between maternal malaise score and sibling death in groups 1 and 2 .

\section{Discussion}

Several previous studies have investigated children's reactions to the death of a sibling, or the effects on a child subsequently born into a family where a child has died or been stillborn. These have taken the form of assertions based on individual professionals' experiences, ${ }^{79}$ uncontrolled studies of children following the sudden death of a sibling in infancy, ${ }^{6}$ or from cancer, ${ }^{8}$ and case reports of children with behaviour problems, ${ }^{4}$ and of adults with psychiatric disorders. $^{5}$

The present study used data about children from a large national cohort who were selected only by week of birth-that is, a total population. This approach is strengthened by the wide range of background social, birth, and health information that can be taken into account when estimating the effect of the death of a sibling on the health, behaviour, and development of the child, and on the mother's state of mind. This study set out to look for the effects of possible confounding factors on a child's reaction to the death of a sibling. Our results confirm the strong association between death in childhood and social disadvantage, and highlight the importance of taking such factors into account when assessing the effects of death in childhood on families.

The three groups of families with dead siblings gave three different viewpoints of the effect of a death in childhood. The families in group 3 (where the adjacent younger sibling had died) included some where the death was a relatively recent event. As a group, these families were socially disadvantaged (table 3), the mothers were more likely to be unsupported by a father figure in the home when the study children were 5 years old, and their malaise scores were significantly higher than those of mothers in control families. The malaise is not wholly explained by social disadvantage, and seems likely to reflect the recent death of a child. The only other positive finding in this group was a higher incidence of bronchitis in the first 5 years.

In those families in which the next older child had died (group 2), most of the deaths occurred before the birth of the study child, the majority in the perinatal period. Maternal malaise was no longer evident, but these families were socially disadvantaged (table 3), and the mothers had fewer educational qualifications compared with the con- 
trol group. The increased rate of maternal smoking during the pregnancy of the study child when the next older sibling had died is an ironic finding. Women's awareness of the adverse effects of smoking in pregnancy and on their children's health was probably not great in 1970 . Smoking in pregnancy and socioeconomic disadvantage are two major predisposing factors to bronchitis and wheezing in the first 5 years. ${ }^{17} 18$ Even allowing for these and other possible intevening variables, however, the death of a sibling seemed to have made a significant contribution in the present analysis. The related stress in the family may be an explanation. ${ }^{14}$

Children in families where a distant older sibling had died (group 1) were no different from controls except that they had a higher incidence of sleeping problems in the first 6 months of life. This finding was only evident in this group; possibly when she was interviewed after a long interval a mother who had experienced a child dying might recall sleeping problems in her surviving child as a manifestation of her concern that that child might also die.

The control groups were chosen to reflect the family composition that would have existed had not a sibling died. In group 3 the numbers of living older siblings in the sibling death and control groups were similar (table 1) suggesting that family size in both the study and control groups was similar. An alternative set of controls (those with the family structure pertaining after the death of a sibling) was also examined; similar results were obtained to those presented in this study.

The family composition of the control groups suggests that families who lost children did attempt to 'replace' them. In group 3, in which the deaths had occurred comparatively recently, the family size (excluding the dead sibling) was smaller than that of controls (table 1). In group 1, where the death had occurred some years earlier, the difference in family size between families where the death had occurred and controls was much smaller. The common absence of father figures in families in group 3 where a recent death had occurred suggests that one consequence of such an event may be the break up of the existing parental relationship. Presumably a further relationship then develops, acounting for the presence of father figures in the families in groups 1 and 2.

Important specific negative findings in our study include the lack of increased rates of early hospital admissions, accidents, and management problems (crying or feeding in the first 6 months), as well as no obvious effect on the child's growth, development, or behaviour at the age of 5 years. Our results do not support the suggestion that families are likely to move house after the death of an infant. ${ }^{6}$
There are obvious limitations to our conclusions. The CHES population studied at five years was only about $80 \%$ of the possible total from the birth study. Those not studied at five years were disproportionally disadvantaged. ${ }^{13}{ }^{14}$ Children with sibling death in these 'missing' families may have exhibited more effects.

Because of the way the data were collected, we were unable to exclude possible effects when an older child dies: such a sibling is likely to have been a longer term companion to the study child and an established family member. Only about $30 \%$ of the siblings died after the age of 7 days and it is probable that most of these would have been 'cot deaths' Thus it is likely that most study children would have had only expectant or transitory contact with their dead siblings. Many of the dead siblings would have died either without an illness, or after only a brief illness; a longer illness might increase the grief reaction in siblings.

Both stillbirth and death in childhood used to be commonplace in this country, and still are in many parts of the world. We believe that our findings support the contention that families usually adapt and adjust to the loss of an infant. Our results, however, only apply to groups; individual families may be devastated by a child's death. We stress the need for adequate support for bereaved families especially in view of the finding that doctors know less, remember less, and seem to be able to think less about mothers who have delivered a stillborn baby. ${ }^{1}$ The study children might also have had grieving reactions that we could not assess, and we cannot exclude behavioural or psychiatric problems later in childhood or in adult life.

We conclude that the stillbirth or death of a new born baby or child has little measurable effect (apart from an increased incidence of wheezing and bronchitis in those immediately before or next born) on the health, behaviour, growth, and development of siblings at the age of 5 in this study population, and using the variables included in the present analyses. We confirm the strong association between stillborn and childhood death, and social disadvantage.

There were measurable early effects on the mother's malaise, an apparent increased likelihood of break up of the existing marriage or relationship, an increased incidence of maternal smoking during the next pregnancy, and eventually the adjustment of family size to compensate for the loss. The finding of an increase in sleeping problems in the first 6 months probably reflects the bias of intervening major family events on the mother's memory. The overall lack of outward effects on the health of other siblings in this study should not discourage professionals from the important task of providing 
appropriate support for parents and families after a stillbirth or the death of a child.

We thank the many funding bodies that supported the 1970 and 1975 surveys of the CHES including the National Birthday Trust Fund, the Medical Research Council, and Action Research for the Crippled Child, and all the midwives, health visitors, and other health workers who collected the data with the cooperation of various administrators in the National Health Service. We also thank Professor NR Butler and other workers in Bristol, where BT and JW (in part) were supported by the Riyadh Al Kharj Hospital Programme.

\section{References}

1 Bourne S. The psychological effects of stillbirths on women and their doctors. J R Coll Gen Pract 1968;16:103-12.

${ }^{2}$ Kennell JH, Slyter H, Klaus MH. The mourning response of parents to the death of a newborn infant. $N$ Engl $J$ Med 1970;283:344-9.

${ }^{3}$ Giles PFH. Reactions of women to perinatal death. Aust NZ J Obstet Gynaecol 1970;10:207-10.

${ }^{4}$ Cain AC, Fast I, Erickson ME. Children's disturbed reactions to the death of a sibling. Am J Orthopsychiatry 1964;34:741-52.

5 Hilgard JR. Depressive and psychotic states as anniversaries to sibling death in childhood. International Psychiatry Clinics 1969;6:197-211.

6 Cornwell T, Nurcombe B, Stevens L. Family repsonse to loss of a child by sudden infant death syndrome. Med J Aust 1977;1: 656-8.
7 Dunlop JL. Bereavement reaction following stillbirth. Practitioner 1979;222:115-8.

8 Pettle MSA, Lansdown RG. Adjustment to the death of a sibling. Arch Dis Child 1986;61:278-83.

9 Cain AC, Cain BS. On replacing a child. J Am Acad Child Psychiatry 1964:3:443-56.

10) Lewis E, Page A. Failure to mourn a stillbirth: an overlooked catastrophe. Br J Med Psychol 1978;51:237-41.

1 Antonovsky A, Bernstein J. Social class and infant mortality. Soc Sci Med 1977;11:453-61.

12 Chamberlain R, Chamberlain G, Howlett B, Claireaux A. British births. The first week of life. 1970. Vol 1. London: Heinemann, 1975.

1.3 Osborn AF, Butler NR, Morris AC. The social life of Britain's five-year-olds. London: Routledge Kegan Paul, 1984.

14 Butler NR, Golding J. From birth to five. Oxford: Pergamon Press, 1986.

15 Chamberlain G, Phillip E, Howlett B, Masters K. British births 1970. Obstetric care. Vol 2. London: Heinemann, 1978.

${ }^{16}$ Baker RJ, Nelder JA. Generalised linear interactive modelling system. London: Royal Statistical Society, 1977.

17 Taylor B, Wadsworth J. Maternal smoking during pregnancy and lower respiratory tract illness in early life. Arch Dis Child 1987;62:786-91.

$1 \times$ Taylor B, Wadsworth J, Golding J, Butler N. Breastfeeding, bronchitis and admission to hospital during the first five years. Lancet 1982;i:1227-9.

Correspondence to Dr J H Baumer, Plymouth General Hospital (Freedom Ficlds and Greenbank), Longficld House, Plymouth PL4 7JH.

Accepted 28 January 1988 